Artículo

Los textos publicados son responsabilidad exclusiva de sus autores

\title{
La motivación al aprendizaje en la Educación Virtual Universitaria
}

\section{Motivation for Learning in Virtual University Education}

\author{
Sara Eliza Morales Morales \\ Maestría en Docencia Universitaria \\ Universidad de San Carlos de Guatemala \\ https://orcid.org/0000-0002-8579-9629 \\ saraelizah@yahoo.com
}

\section{Referencia}

Morales Morales, S. E. (2021). La motivación al aprendizaje en la Educación Virtual Universitaria. Revista Guatemalteca de Educación Superior, 4(2), 42-49.

DOI: https://doi.org/10.46954/revistages.v4i2.61

Recibido: 15/02/2021

Aceptado: 04/04/2021

\section{Resumen}

El estudio se realizó debido a la necesidad e importancia de conocer el impacto que ha tenido la pandemia COVID-19 en la motivación para el aprendizaje del estudiante universitario a través de la educación virtual, tomando en cuenta que esta forma de educación, surgió por la necesidad del surgimiento del primer caso de Coronavirus en el país, es así como las autoridades de la Universidad de San Carlos de Guatemala, deciden suspender en marzo de 2020 todas las actividades presenciales, esta migración de educación presencial a virtual, fue de inmediato, fue por esa situación que se decidió realizar un estudio en donde se evidencie la situación del estudiante universitario y cómo ha estado en relación a motivación dentro de su aprendizaje. El estudio se realizó desde el enfoque cualitativo, de tipo exploratorio, con diseño fenomenológico, utilizando un tipo de muestra no probabilística, por voluntarios. 
Dentro de los principales hallazgos se puede mencionar que el estudiante universitario tuvo que sobrellevar distintos factores que afectaron la motivación de su aprendizaje, como el propio virus, el encierro, el acceso a internet, el factor económico, familiar, etc., pero además se encuentran las motivaciones intrínsecas que hacen que el estudiante siga con sus metas de educación. A pesar de lo ya mencionado, la motivación del estudiante con respecto a su aprendizaje se mantuvo hacia el cumplimiento de metas.

\section{Abstract}

The study was carried out due to the need and importance of knowing the impact that the COVID-19 pandemic has had on the motivation for university student learning through virtual education, taking into account that this form of education arose from the The need for the emergence of the first case of Coronavirus in the country, is how the authorities of the University of San Carlos de Guatemala, decide to suspend in March 2020 all face-to-face activities, this migration from face-to-face to virtual education, was immediately, was Due to this situation, it was decided to carry out a study where the situation of the university student and how it has been in relation to motivation within their learning is evidenced. The study was carried out from a qualitative, exploratory approach, with a phenomenological design, using a type of non-probabilistic sample, by volunteers. Among the main findings it can be mentioned that the university student had to cope with different factors that affected the motivation of their learning, such as the virus itself, confinement, access to the internet, the economic factor, family, etc., but also, they find the intrinsic motivations that make the student continue with their educational goals. Despite the, the student's motivation regarding his learning was maintained towards the fulfillment of goals.

\section{Palabras clave:}

pandemia, COVID -19, motivación, educación, educación virtual

\section{Keywords:}

pandemic, COVID -19, motivation, education, virtual education 


\section{Introducción}

Según la Organización Mundial de la Salud (OMS), El COVID 19 es la enfermedad infecciosa causada por el coronavirus que se ha descubierto más recientemente. Actualmente es una pandemia, por ser altamente infecciosa, por tal razón se han tomado medidas restrictivas, como aislamiento social a nivel mundial.

Debido a lo anteriormente mencionado y presentándose el primer caso de la enfermedad en Guatemala, en marzo de 2020, una de las actividades que se vio directamente afectada fue la educación, en todos los niveles educativos, incluyendo la Educación Universitaria.

La Universidad de San Carlos de Guatemala, suspendió actividades presenciales académicas y administrativas, para cuidar la integridad de los estudiantes y el personal administrativo, esto trajo consigo que todas las actividades académicas se trasladaran a modalidad virtual o en línea, situación que afectó la motivación del estudiante, por los diversos factores que se presentaron derivados de la pandemia. Se entiende como motivación: Estado interno que activa, dirige y mantiene el comportamiento. (Woolfolk, 2010, p. 376).

En el Modelo de Aprendizaje Motivado plantea que existe una relación estrecha entre la motivación y el aprendizaje, que se influyen mutuamente. La motivación de los estudiantes puede influir en lo que aprenden y en cómo lo aprenden. A su vez, a medida que los estudiantes aprenden y perciben que se vuelven cada vez más hábiles, se sienten motivados para seguir aprendiendo. (Schuk 2012, p. 356).

Por eso el interés de la presente investigación es analizar ¿Cómo ha impactado la pandemia del COVID 19 en la motivación al aprendizaje en la Educación Virtual Universitaria? en los Estudiantes de la Carrera de Ciencias Psicológicas del Centro Universitario de Sacatepéquez -CUNSAC-.

Para esta investigación se utilizó un enfoque de investigación cualitativo, con lo cual se buscó analizar y comprender las percepciones y experiencias de los estudiantes y docentes, 
con un diseño fenomenológico, utilizando una muestra no probabilística por voluntarios, los instrumentos que se utilizaron fueron las entrevistas semiestructuradas las cuales estuvieron dirigidas a estudiantes, docentes y coordinador, por medio de formularios Google.

\section{Materiales y métodos}

La investigación se realizó con un alcance exploratorio utilizando una metodología con enfoque cualitativo, diseño de tipo fenomenológico. Para la población se seleccionaron estudiantes de dos semestres, sexto y octavo de la carrera en la licenciatura en Psicología, del Centro Universitario de Sacatepéquez. Utilizando un tipo de muestra no probabilística, por voluntarios.

\section{Resultados}

Los resultados obtenidos en relación con el objetivo: Analizar el Impacto de la pandemia COVID-19 en la motivación al aprendizaje en la educación virtual universitaria, se obtuvieron mediante la aplicación de entrevista semiestructurada la cual fue aplicada por medio de un formulario de Google, medida que se tomó debido al aislamiento social que se estaba viviendo.

Tabla No.1 Factores que afectan la motivación al aprendizaje en la educación virtual universitaria en tiempos de pandemia COVID-19

\begin{tabular}{|c|c|c|}
\hline Categorías & $f$ & Evidencia \\
\hline \multirow[t]{5}{*}{ Económico } & $5 / 24$ & $\begin{array}{l}\text { "En lo económico fue muy difícil, ya que no contaba con servicio de } \\
\text { internet". }\end{array}$ \\
\hline & & "Ha decaído, se ve afectado por la economía". \\
\hline & & $\begin{array}{l}\text { "Ya no es la misma motivación porque se piensa en como ir sobresaliendo } \\
\text { en casa hay muchas más prioridades alimentación, pagas de Luz, agua, e } \\
\text { internet para asistir a las clases virtuales". (sic). }\end{array}$ \\
\hline & & $\begin{array}{l}\text { La falta de trabajo cambiaba igualmente la motivación hacia las } \\
\text { actividades universitarias". (sic). }\end{array}$ \\
\hline & & $\begin{array}{l}\text { "En el lado económico, ya que soy solo el que aporto la economía a mi } \\
\text { familia y sus necesidades". (sic). }\end{array}$ \\
\hline
\end{tabular}




\begin{tabular}{ll}
\hline Emocionales $\quad 5 / 24 \quad$ "En los últimos meses, el encierro ha provocado que mi estado de ánimo \\
se vea afectado". \\
"El factor estresante que genera estar en casa disminuye el nivel de \\
atención en clases". \\
"Una de mis hijas presentó estrés crónico y ya no estudiaba por atender \\
la U". (sic). \\
"A pesar de que no he convivido con algún familiar infectado de \\
la COVID19 la especulación, las noticias y los pensamientos de \\
desesperanzas se apoderan de mi mente, eso de alguna forma copta mi \\
atención y mis ganas de hacer algún trabajo universitario, muchas de las \\
veces". (sic). \\
"Uno de los principales aspectos que considero afectó mi motivación, es \\
el hecho de permanecer encerrado".
\end{tabular}

Comunicación/ 5/24

interacción "l hecho de permanecer encerrado".

"Las barreras de comunicación".

"Por medio de las clases virtuales es más complicado poder comunicarse con los docentes".

"La convivencia con los compañeros es esencial".

"Es el hecho de permanecer encerrado y ya no estar en contacto con mis compañeros".

Tareas $5 / 24 \quad$ "Creo que al principio de la cuarentena fue desmotivante porque no
estábamos acostumbrados a las clases en línea". (sic).
"Mi motivación se ha visto afectada cuando algunos docentes abusan
de tareas o proyectos".
"La realización de los trabajos, tareas y exposiciones es más complicado
y por lo cual es muy difícil realizar y obtener los puntos de las tareas".
"En aprendizaje y conocimiento no me ha afectado, pero ponerlo en
práctica me ha costado..." (sic)
"Causó un retraso en lo aprendido".
"También desmotiva que el internet falle porque la explicación de los
Lics. nos llega a medias". (sic).
internet
"En lo económico fue muy difícil, ya que no contaba con servicio de
internet".
"Ha afectado en las clases ya que con la modalidad virtual ha fallado la
señal".
"La limitación del acceso a internet, impidiéndome la conexión eficiente,
por lo mismo pierdo el interés al tener una señal inestable y con ello
perder más secuencia de los contenidos trabajados". (sic).




Cansancio $3 / 24 \quad$ "La cantidad de horas al día tras una computadora ha afectado mi
motivación de aprendizaje porque llega a ser muy cansado".
"Ya no es la misma motivación porque se piensa en como ir sobresaliendo
en casa hay muchas más prioridades, pagas de Luz, agua, e internet para
asistir a las clases virtuales, después de todo eso de lo cansado ya no se
tienen energía para las actividades universitarias".
"A veces no tengo ninguna motivación, es muy duro trabajar todo el día
frente a un monitor y luego estudiar frente otro".

$\begin{array}{lll}\begin{array}{l}\text { Dificultad para } \\ \text { concentrarse }\end{array} & 2 / 24 & \text { "El factor estresante que genera estar en casa disminuye el nivel de } \\ \text { atención en clases". } & \\ & \text { "Ha sido complicado ya que soy una persona a la que le cuesta trabajo } \\ & \begin{array}{l}\text { concentrarse y estando embarazada casa con tantos distractores me es } \\ \text { difícil". }\end{array}\end{array}$

"A pesar de que no he convivido con algún familiar infectado de la COVID19 la especulación, las noticias y los pensamientos de desesperanzas se apoderan de mi mente, eso de alguna forma copta mi atención y mis ganas de hacer algún trabajo universitario". (sic).

\begin{tabular}{|c|c|c|}
\hline Dispersión & $1 / 24$ & $\begin{array}{l}\text { "Ya que no cuento con un contexto formal, mi atención es dispersa en los } \\
\text { diferentes estímulos de un ambiente hogareño". }\end{array}$ \\
\hline
\end{tabular}

Fuente: Datos obtenidos por medio de entrevista a estudiantes de la carrera de ciencias psicológicas, Centro Universitario de Sacatepéquez.

\section{Discusión}

Los hallazgos del trabajo se consideran evidencia científica, destacando como primer punto el factor económico, es de recordar que, debido a las medidas de prevención como el aislamiento social, afectaron diversos empleos, provocando una crisis económica, otro factor a destacar es el impacto de esta pandemia a nivel emocional, la falta de comunicación e interacción, adaptarse a una nueva forma de trabajo, el acceso a internet y el tipo de tareas, también son otros factores destacables.

La problemática radica en los factores económicos y de conectividad en la internet, causando una inestabilidad en el proceso de enseñanza-aprendizaje en los estudiantes.

Durante este tiempo, las instituciones educativas de las zonas afectadas están buscando soluciones provisionales para seguir enseñando, pero es importante señalar que la calidad del 
aprendizaje depende del nivel de acceso y eficiencia digital. El entorno de aprendizaje en línea varía profundamente de la situación tradicional del aula en lo que respecta a la motivación, la satisfacción y la interacción del alumno (Bignoux \& Sund, 2018). La motivación del estudiante con respecto a la educación virtual universitaria en tiempos de pandemia va a depender de factores internos como externos, propios a las necesidades personales de cada uno de ellos.

\section{Agradecimientos}

Se agradece el apoyo de las autoridades del Centro Universitario de Sacatepéquez, por haber otorgado el permiso para la aplicación de técnicas de recolección de datos que fueron la base para la investigación, así como para el presente artículo.

\section{Referencias}

Bignoux, S., \& Sund, K. J. (2018). Tutoring executives online: what drives perceived quality?. Behaviour \& Information Technology, 37(7), 703-713. doi: 10.1080/0144929X.2018.1474254

Schunk, D. H. (2012). Teorías del Aprendizaje (Sexta ed.). México: Pearson Educación.

Woolfolk, A. (2010). Psicología Educativa (Decimoprimera ed.). Mexico: Pearson Educación. 


\section{Sobre la autora}

\section{Sara Eliza Morales Morales}

Es Psicóloga de profesión y Docente Universitaria, en relación con eso decido cursar la Maestría en Docencia Universitaria en la Universidad de San Carlos de Guatemala, en la Escuela de Estudios de Postgrado, Facultad de Humanidades, en relación al cambio en la forma de aprendizaje que se está dando con respecto a la Pandemia COVID-19 surge el tema de investigación: "Motivación al aprendizaje en la Educación Virtual Universitaria" del cual se desprende este artículo científico.

Copyright (c) Sara Eliza Morales Morales

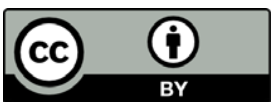

Este texto está protegido por una licencia CreativeCommons 4.0.

Usted es libre para compartir, copiar y redistribuir el material en cualquier medio o formato y adaptar el documento, remezclar, transformar y crear a partir del material para cualquier propósito, incluso comercialmente, siempre que cumpla la condición de atribución: usted debe reconocer el crédito de una obra de manera adecuada, proporcionar un enlace a la licencia, e indicar si se han realizado cambios. Puede hacerlo en cualquier forma razonable, pero no de forma tal que sugiera que tiene el apoyo del licenciante o lo recibe por el uso que hace. 